\title{
BRONSON PRICE: 1905-1978
}

\section{In Memoriam}

\section{GORDON ALLEN}

National Institute of Mental Health, NIH, Rockville, Maryland, USA

It is likely that the best-known paper on twins, at least in the English language, is " Primary biases in twin studies". Although published as a review, it was more nearly a monograph and presented the most thorough discussion, then or now, of the potential effects of intrauterine phenomena on twin differences after birth. The paper called attention to peculiarities of development in twins: lateral inversions, shared circulation, and complications of delivery, and explored the consequences of each. In particular, it suggested that imbalance in the shared circulation of monochorionic monozygotic (MZ) twins was likely to produce differences within pairs that would be mistaken for effects of postnatal environment.

The author of this paper was born in Freeport, Illinois. He attended Antioch College and Stanford University, where he obtained a Ph.D. degree in psychology and biometrics in 1934. During two years in Europe as a fellow of the Social Science Research Council, mostly in Moscow, he made the close friendship of H.J. Muller. His association with geneticists continued after he returned to the USA and became an instructor in psychology at the Ohio State University. In two brief papers of that period he applied a genetic point of view to the then fresh debate about a general factor, " $\mathrm{g}$ ", in intelligence.

In 1940 he published, with Sidney Halperin, a thoughtful analysis of the efficacy of sterilization in reducing mental deficiency. The paper challenged one by R.A. Fisher titled, "The elimination of mental defect", and gave very good reasons for opposing compulsory sterilization laws. The arguments are still cogent and relevant. Before leaving Ohio, Price undertook a twin-control experiment which could well serve as a paradigm, comparing the facility with which identical twins learned two contrasting versions of Interlingua.

Early in 1941 he took leave from Ohio State to work as a personnel technician with the War Department in Washington. He was then caught up in the war effort, mainly interpreting radio broadcasts from eastern Europe for the Office of War Information. At the end of hostilities he did not return to academe, but served successively as a Social Science Analyst in the National Office of Vital Statistics, an Analytical Statistician in the Children's Bureau, and a Survey Statistician in the Office of Education. His official work in these positions appeared in government documents; the few which credit his authorship are not cited below because they do not relate to genetics.

Although he worked most of his life as a statistician, Bronson Price's dearest scientific interest remained behavioral genetics. Perhaps partly because of his closeness to Hermann Muller, Price was among the founders of the American Society of Human Genetics in 1948 . He served on the original Boards of Editors and of Directors.

The seed for the Primary Biases paper was probably sowed at the Medico-Genetical Institute in Moscow, where the importance of the mutual circulation for surviving twins was discounted. 
He did not, however, decide at that time to write such a paper, and the long delay before the paper appeared also reflects the exhaustive literature search which is evident in the paper. The published bibliography contained some 350 concise references, and Price's personal list of relevant articles and books, published elsewhere in this journal, included another 260. Many of these articles were in German or French and hence known poorly or not at all to many English-speaking scientists.

Besides reviewing and integrating the literature on prenatal and natal phenomena peculiar to twins, Price called for systematic studies to relate these phenomena to postnatal differences and for separate analysis of data on monochorionic and dichorionic MZ twins. The paper appeared at a favorable juncture for the acceptance and application of his recommendations. Edith Potter was reporting and still pursuing her studies of twin pregnancies in Chicago. Norma Ford Walker in Toronto was collecting data on consecutive multiple births with the intention of subsequent follow-up. Planning had not yet begun for the massive Collaborative Perinatal Project, undertaken before the end of the decade under the direction of the U.S. Public Health Service.

Of the people involved in these studies, some were already well aware of the published findings, mainly those of the German obstetrician Friedrich Schatz, but Price's article reinforced their interest and stimulated other scientists to undertake related research. The interest generated in the 1950's is only now coming into fruit. The research called for was difficult, requiring accurate observations on a large series of twin afterbirths and precise diagnosis of zygosity on the same-sex pairs. The critical psychological questions could be answered only after the twins had passed through childhood.

The findings now emerging with regard to birth weight, postnatal growth, and behavior are more complicated than Price foresaw. Although MZ twins with one chorion and a shared circulation do tend to have larger differences in weight and head circumference at birth, dichorionic $\mathrm{MZ}$ pairs manifest important differences also and seem to retain those differences longer. The story is further complicated by race and sex differences, and some workers still question the accuracy of classification of the membranes in available twin series.

Price's article on primary biases is now receiving less notice among younger twin scientists, but the issues he outlined are still very much alive. Current research and imminent publications seem likely to throw new light not only on twin differences, but on more general phenomena of fetal and infant development.

\section{Publications of Bronson Price, excluding government documents:}

1935 A proposed method for the direct measurement of correlation. Science, 82: 497-498. B. Price.

1936 Homogamy and the intercorrelation of capacity traits. Ann. Eugen., 7: 22-27. B. Price.

1937 A note on Professor Tryon's theory of intercorrelation. Psychol. Rev., 44: 183-187. B. Price.

1937 USSR Notes. Unpublished but copyrighted by B. Price. Circa 9,500 words.

1938 Twin light on nature versus nurture. (Book review) Jour. Hered., 29: 21-26. D.C. Rife, B. Price and L.H. Snyder.

1940 Sterilization laws - Bane or banner of eugenics and public welfare? Am. J. Ment. Def., 45: 134-144. B. Price and S.L. Helperin.
1944 A twin-controlled experiment on the learning of auxiliary languages. Genet. Psychol. Monographs, 29: 117-154. B. Price, W.J. Kostir and W.M. Taylor.

1948 Toward reducing ambiguities in twin studies. Eighth Int. Congress of Genetics, Stockholm. (1949, Hereditas, 35 (Supp.): 643-644). B. Price.

1950 Primary biases in twin studies; a review of prenatal and natal difference-producing factors in monozygotic pairs. Am. J. Hum. Genet., 2: 293-352. B. Price.

1954 Longitudinal data on eruption and attack of the permanent teeth. Jour. Dent. Res., 33: 65-79. J.T. Fulton and B. Price. 